\title{
CARTA A LOS PROFESORES
}

$\Lambda$ preciado profesor:

En este lento proceso de desnaturalización del hombre y de sus instituciones, es necesario detenerse un rato en el camino y reflexionar sobre nuestra Universidad, buscancio su naturaleza original. El conocimiento debe ser el eje fundanental que regula las actividades universitarias. Conocimiento para ensanchar la conciencia del hombre. En fin de cuentas, este último proceso ha sido la base de toda la aventura humana.

En los recintos de la Universidad se imparte conocimiento: docencia; se crea nuevos conocimientos: investigación, y se comparte conocimientos: extensión. La docencia universitaria se levanta sobre el conocimiento más avanzado, factible de imprimir progreso al entorno social. Lo más avanzado en la ciencia, el arte, la tecnología, la filosofía, la religión... del mundo contemporáneo, soure los rieles de metodologías igualmente avanzadas. La investigación universitaria desentraña los problemas acuciantes del entorno empleando los métodos investigativos más eficaces y más desarrollados, factibles de ser asimilados creadoramente por la institución. La extensión universitaria es la socialización del conocimien- 
to mediante el cual se combate todos los males de la comunidad buscando elevarla a un nivel más humano. Sólo así, la Universidad puede convertirse en una real alternativa de desarrollo material y espiritual de la sociedad que la generó.

La Universidad Surcolombiana no se halla, sin embargo, en este nivel. La docencia, con algunas excepciones, es repetitiva de conocimientos desenraizados de nuestra realidad y en muchos casos, obsoletos. La investigación es deficiente en cantidad y carece aún de métodos científicos medianamente desarrollados. La proyección comunitaria es incipiente y con excepción de algunos proyectos, la inmensa actividad universitaria fenece en los límites de sus paredes. Es una institución hacia el interior.

Es la crisis de la Universidad, no solamente de la Surcolombiana sino la de todo el país; incluyendo la pública y la privada. Tal vez acentuada más en la primera que en la segunda. Es también la crisis de toda la educación colombiana que a su vez, hace parte de la gran descomposición social de un sistema que se degrada ante la mirada impotente de los colombianos.

Evidentemente es una figura literaria, mal comprendida, cuando se habla de la crisis de la Universidad. Es una forma sutil de evadir responsabilidad porque no es la institución la que está en crisis, en primer lugar, sino sus profesores, estudiantes, trabajadores y directivos. La Universidad se ha convertido en el centro donde convergen los más intrincados intereses; desde los más personales hasta los más colectivos, de grupos, internos y externos. Prevalecen sobre la necesidad universitaria de desarrollar el conocimiento humano. Son las personas y no la institución, las llamadas a aceptar, en serio, un profundo proceso de transformaciones en su vida profesional.

La crisis es una anormalidad y el tiempo que nos toque convivir con ella depende de nuestra voluntad; primero, de reconocer en dónde estamos; segundo, de transformarnos hacia un ideal más universitario. En fin de cuentas, somos los artífices de nuestros propios destinos académicos. Por ahora, contamos con un anteproyecto de auto-evaluación de la Facultad de Educación que congrega esos dos objetivos. Necesitamos, con urgencia, transformaciones sustanciales y no mecánicas. Es la oportunidad de llamar a la voluntad profesional de los profesores de Educación para que participen creadoramente, en la autoevaluación. También, a las Directivas universitaria para que comprendan $y$ apoyen nuestras necesidades de transformación por encima de intereses diferentes a los académicos. Sólo con el soporte auténtico de estos dos sectores será posible avanzar en la calidad de la Facultad de Educación. 
Es tiempo suficiente para que la Facultad de Educación tenga su propia revista. Contamos con condiciones favorables: problemas socio-educativos de palpitante actualidad, un buen número de profesores adscritos a los diferentes programas de la Facultad, crisis compleja que nos está consumiendo, profesores especializados en temas educativos, etc. Por estas razones. el Consejo de Facultad decidió institucionalizar la revista "PAIDEIA", de estructura temática y de aparición trimestral. "La calidad de la educación en la Universidad Surcolombiana" fue el primer tema seleccionado en concordancia a la discusión nacional tanto de FECODE como del MEN, del ICFES, y de las Universidades del país. La respuesta fue fría. Sólo apareció un trabajo. Algo falló Tal vez, los Jefes de Programa no le hicieron el suficiente despliegue ante los profesores. Quizás los profesores no están interesados en escribir sobre ese tema. Algo nos fracasó y tal vez este sea un ejemplo más de la crisis en cionde estamos hundidos. Mientras reflexionamos sobre el terra, deber.os concluir que la Facultad de Educación no tiene quien le escriba. ;Tanta es su soledad!

Tuvimos necesidad de tomar materiales existentes de una revista programada en la anterior administración de la Facultad. Seleccionamos los artículos cortos, inéditos y de actualidad. Ahora se la presentamos para que la juzgue. Cualquiera que sea el resultado, es necesario recordar que es nuestra revista y ha sido elaborada, de una o de otra manera, por todos nosotros.

Finalmente, persistiremos en el mismo tema para el próximo número. Deseamos resolver incógnitas de nuestro más vivo intelés ¿Cúal es la calidad de la educación en la ITniressidad Surcolombiana? ¿Existe calidad en nuestra educación? ¿No estaremos ejerciendo nuestra profesión con una actitud y una práctica medianera? ¿Cuáles serian las razones para que !a educación de la re la USCO no esté resolviendo problemas reales de nuestra comunidad? Estas y otras preguntas son pertinentes a los profesionales de la educación. La revista está a su disposición. Descle ainora esperamos su colaboración para abrirnos caminos en un momento donde se necesita el concurso de todos, con madurez y actitud realmente democrática.

\section{JORGE ELIAS GUEBELLY ORTEGA Jecano Facultad de Educación}

